\title{
Erratum
}

\section{Vector solitons in femtosecond fibre lasers}

W.C. Chen ${ }^{\mathrm{a}}$, W.C. Xu ${ }^{\mathrm{b}}$, F. Song, M.C. Shen, D.A. Han, and L.B. Chen

Eur. Phys. J. D. 48, 255-260 (2008) DOI: 10.1140/epjd/e2008-00048-8

Received 8 October 2008

(c) EDP Sciences, Società Italiana di Fisica, Springer-Verlag 2008

There was an error in reference [19] [Phys. Rev. E 75, 016611 (2007)], cited in our paper [Eur. Phys. J. D 48, 255 (2008)]; specifically the author's last names were replaced by their first names. The correct reference [19] is as follows:

19. M. Delqué, G. Fanjoux, T. Sylvestre, Phys. Rev. E 75, 016611 (2007)

We apologize to the authors for the error made.

\footnotetext{
${ }^{a}$ e-mail: chenwch@163.com

b e-mail: xuwch@scnu.edu.cn
} 